\title{
Serebral Palsili Çocukların Mobilite Düzeyleri İle Toplumsal Katılım Becerileri Arasındaki İlişki
}

The Relationship between Mobility Level and Social Participation in Children with Cerebral Palsy

\author{
Gökçen AKYÜREK ${ }^{1}$, İsa UYKUN ${ }^{2}$, Gonca BUMiN ${ }^{3}$ \\ ${ }^{1}$ Dr.Fzt., Hacettepe Üniversitesi Sağlık Bilimleri Fakültesi Ergoterapi Bölümü, Ankara \\ ${ }^{2}$ Erg., Hacettepe Üniversitesi Sağlık Bilimleri Fakültesi Ergoterapi Bölümü, Ankara \\ ${ }^{3}$ Prof.Dr., Hacettepe Üniversitesi Sağlık Bilimleri Fakültesi Ergoterapi Bölümü, Ankara
}

\section{öz}

\begin{abstract}
Amaç: Bu çalışmanın amacı serebral palsili (SP) çocukların mobilite düzeyleri ile toplumsal katıım becerileri arasındaki ilişkiyi incelemektir. Gereç ve Yöntem: Teknik lisede okuyan serebral palsili öğrenciler $(n=13$, yaşları 15-18) çalışmaya dahil edildi. Lokomosyon becerileri ABILOCO-Çocuk ölçeği ve katılım düzeyi için Çocuk ve Ergen Katılımı Ölçeği (CASP) kullanıldı. ABILOCO-Çocuk ölçeği, ebeveynlerin, SP'li çocuklarda çok çeşitli hareket becerilerini ölçmek için tasarlanmış iyi psikometrik özelliklere sahip bir görüşme ölçeğidir. Sonuçlar: Çalışmamızın sonucunda, lokomosyon becerileri ile sosyal katılım arasında istatistiksel olarak anlamlı bir ilişki tespit edildi $(r=0,789 ; p<0,001)$. En yüksek korelasyon ev ve okul katılım alt ölçekleri olarak belirlendi (sırasıyla $r=0,948 ; r=0,908 p<0,001$ ). Tartışma: Çocukların mobilite düzeyleri sosyal katılımı direkt etkileyen bir parametredir. Illeride yapılacak çalışmalarda sosyal katıımı etkileyen erişilebilirlik ve güvenlik gibi diğer faktörlerin de ele alınmasının önemli olduğu düşünülmektedir.
\end{abstract}

Anahtar Kelimeler: Mobilite; Katılım; Serebral palsi

\section{ABSTRACT}

Purpose: The aim of this study was to examine the relationship between mobility levels and social participation of children with cerebral palsy. Materials and Methods: The participants ( $n=13$, aged 15-18 years old) who were included in the study were studying in technical high school. For locomotion skills, ABILOCO-Kids questionnaire was used and for participation, Child and Adolescent Participation Scale (CASP)" was used. The assessment forms were filled in by the children's parents. ABILOCO-Kids questionnaire is a parent's interview based questionnaire which has good psychometric qualities for measuring a wide range of locomotion abilities in children with CP. Results: As a result of our study, a statistically significant relationship has been determined between mobility skills and social participation skills $(r=0.789 ; p<0.001)$. The strongest correlation was identified as home and school participation subscales $(r=0.948 ; r=0.908 p<0.001$ respectively). Conclusion: As seen in the conclusion, social participation skills are related to mobility skills. Further data are needed to assess other aspects such as accessibility and security.

Keywords: Mobility; Participation; Cerebral palsy

Sorumlu Yazar (Corresponding Author): Dr. Fzt. Gökçen AKYÜREK e-mail: gkcnakyrk@gmail.com ORCID ID: 0000-0002-0309-2321

Geliş Tarihi (Received): 11.03.2018; Kabul Tarihi (Accepted): 08,05.2018

Bu araştırmanın özeti 23-24 Şubat 2018 tarihinde 7. Uluslararası Hıfzı Özcan Serebral Palsi Kongresinde poster olarak sunulmuştur. 
Bu çalışmadaki amacımız serebral palsili (SP) 1518 yaş arası çocukların mobilite düzeyleri ile toplumsal katııım becerilerinin arasındaki ilişkiyi incelemektir. Serebral palsi (SP): prenatal ve perinatal zamanda beynin bir bölgesindeki hasar nedeniyle ortaya çıkan kas kontrol yetersizliğidir. SP'ye neden olan hasarlar prenatal, perinatal ve postnatal zamanda oluşabilir (Swaiman; Ashwal,1994 ). SP'li çocuklarda güçsüzlük, sertlik, yavaşlık, titreme ve denge bozukluğu gibi pek çok sorun gözlenebiliyor. Bu bulgulara ek olarak motor bozukluklar, metal retardasyon, konuşma bozukluğu, öğrenme güçlüğü, dikkat bozuklukları, yutma güçlüğü, işitme bozukluğu, iletişim güçlüğü görülebilir (Morris, 2002). SP'de görülen motor bozukluklar sonucunda bireyin katıım becerileri etkilenmektedir. Katılım becerileri evde katıım, okulda katıım, mahalle katıımı ve toplum katıımı olarak incelenebilir. Tüm bu katılım alanlarında SP'li çocuklar ve bireyler problem yaşayabilmektedirler (Imms, Reilly, Carlin, \& Dodd, 2008). SP'nin bulguları olan kas kontrol yetersizliği, motor bozukluklar mobilite yeteneklerinde de problemler oluşturmaktadır. Katıım becerilerinin artırılabilmesi için mobilite becerileri de yeterli seviyede olmalıdır. Yardımcı cihazlar ile yürümesi mümkün olan çocuklarda ise katılım becerilerinde artış görülmektedir (Palisano ve ark, 2003). Toplumsal katılım; bireyin kendi aktivitelerini yeterli düzeyde yapabilmesidir. SP çocukların fiziksel, sosyal ve davranışsal çevresi günlük aktiviteler ve sosyal rollere katımalarını etkilemektedir (Colver ve ark, 2014). Ergoterapist müdahaleleri günlük yaşam aktivitelerine toplumsal katıımı artııcı amaçlar içermekte olduğu için yardımcı cihazla ya da yardımcı cihaz olmaksızın mobilite becerilerini artırabilirler. Çevre düzenlemeleri, aile eğitimi aktivite katılımı ergoterapistler çok önemsemektedirler ve bu alanlarda düzenlemeler ile toplumsal katımı artırabilirler ( Üstdağ \& Bumin, 2014). Yapılan literatür taramasında mobilite ile toplumsal katııım becerilerinin ilişkisini inceleyen çalımalar bulunmamıştır (Shikako Thomas, Majnemer, Law \& Lach, 2008). Çalışmamızın hipotezi: SP'li çocukların mobilite düzeyleri ile toplumsal katııım becerileri arasında herhangi bir ilişki yoktur.

\section{GEREÇ VE YÖNTEM}

Çalışmamızda $15-18$ yaş arası $(15,53 \pm 1,19) 13$ SP'li çocukların velileri ile değerlendirmeler yapıldı. Çalışma Helsinki Deklerasyon Kriterlerine uygun olarak hazırlandı. Olguya ve ailesine çalışma ile ilgili bilgi verildi ve rıza formu ile gönüllü katııım formu imzalatıldı. Değerlendirmeler velilere anlatıldı ve doldurmalarına yardımcı olundu. Değerlendirmeler Karakusunlar IMKB Teknik ve Endüstri Meslek Lisesin de yapıldı. Kullanılan değerlendirmeler; çocuk adölesan katılım ölçeği (CASP), ve ABILOCO-Çocuktur.

Çocuk ve Adolesan Katıım Skalası (CASP): Bu test aile tarafından verilen bilgiye göre çocukların ev, okul, toplumsal aktivitelere katılımını ölçen bir testtir. 20 Sıralı ölçekli maddeden ve dört alt bölümden oluşmaktadır: 1) Evde Katıım (6 madde), 2) Mahalle ve Toplum Katıımı (4 madde), 3) Okul Katıımı (5 madde) ve 4) Ev ve Toplum Yaşam Faaliyetleri (5 madde). 20 madde beş puanlık bir ölçekte derecelendirilir: Yaşına uygun (tam katıım), biraz kısıtlı, çok kısıtlı, yapamaz, uygulanamaz (aktivitelere katıımı beklenemez). 5 yaş ve üzeri çocuklara uygulanabilir.

ABILOCO-çocuk (hareket kabiliyetini ölçen): ABILOCOçocuk 10 öge üzerinde tanımlı geçerli ve güvenilir lokomosyon yetenekleri ölçeğidir. Hareket kabiliyetini ölçen ABILOCO-çocuk Türkçeye çevrilerek uygulandı. On sorudan oluşan ABILLOCO-kids anketi velilerin vermiş olduğu bilgilere göre dolduruldu. Sorular beş puanlık ölçekte değerlendirilir. İmkânsız, zor, kolay, (gözlemlenmemiş aktivite). 5 yaş ve üzeri çocuklara uygulanabilir.

\section{Istatistiksel analiz}

İstatistiksel analizler için "IBM SPSS 23 for Windows" programı kullanıldı. Korelasyon için Spearman korelasyon testi kullanıldı. İstatistiksel anlamlılık düzeyi $\mathrm{p}<0,05$ olarak kabul edildi.

\section{SONUÇLAR}

Katılımcıların CASP ve ABILOCO-Çocuk değerlendirmelerinden almış oldukları sonuçlar Tablo 1 'de verilmiştir. ABILOCO-Çocuk değerlendirmesi CASP değerlendirme sonuçlarının korelasyon sonuçları Tablo 1 de verilmiştir. Tablo 2 de görüldüğü gibi toplumsal katıımları ile mobilite düzeyleri arasında pozitif yönelimli anlamlı bir ilişki bulunmuştur. Korelasyon sonuçları 0,75 > olduğu için ilişki oldukça kuvvetli çıktı denilebilir. 
Tablo 1. Katılımcıların CASP ve ABILOCO-Çocuk değerlendirmelerinden almış oldukları puanlar

\begin{tabular}{lllllll}
\hline Katılımcı & abıloco & casp - ev & casp-okul & casp- mah. & casp-ev ve toplumsal & Toplam \\
\hline $\mathbf{1}$ & 17 & 87 & 81 & 85 & 85 & 85 \\
\hline $\mathbf{2}$ & 14 & 95 & 93 & 90 & 90 & 92 \\
\hline $\mathbf{3}$ & 10 & 91 & 56 & 75 & 80 & 77 \\
\hline $\mathbf{4}$ & 0 & 66 & 62 & 75 & 40 & 61 \\
\hline $\mathbf{5}$ & 0 & 54 & 56 & 65 & 65 & 60 \\
\hline $\mathbf{6}$ & 9 & 83 & 56 & 70 & 60 & 68 \\
\hline $\mathbf{7}$ & 17 & 95 & 68 & 75 & 55 & 75 \\
\hline $\mathbf{8}$ & 20 & 100 & 100 & 80 & 90 & 97 \\
\hline $\mathbf{9}$ & 17 & 100 & 93 & 100 & 95 & 97 \\
\hline $\mathbf{1 0}$ & 3 & 63 & 62 & 60 & 40 & 56 \\
\hline $\mathbf{1 1}$ & 0 & 63 & 62 & 60 & 55 & 60 \\
\hline $\mathbf{1 2}$ & 17 & 100 & 100 & 100 & 100 & 100 \\
\hline $\mathbf{1 3}$ & 0 & 66 & 56 & 70 & 40 & 58 \\
\hline
\end{tabular}

Tablo 2. Korelasyon sonuçları

\begin{tabular}{lllllll}
\hline & & $\begin{array}{l}\text { Evde } \\
\text { katılım }\end{array}$ & $\begin{array}{l}\text { Okul } \\
\text { katılımı }\end{array}$ & $\begin{array}{l}\text { Mahalle } \\
\text { ve toplum } \\
\text { katılımı }\end{array}$ & $\begin{array}{l}\text { Ev ve toplumsal } \\
\text { yaşam } \\
\text { faaliyetleri }\end{array}$ & $\begin{array}{l}\text { CASP } \\
\text { TOPLAM } \\
\text { PUAN }\end{array}$ \\
\hline $\begin{array}{l}\text { ABİLOCO- } \\
\text { Çocuk }\end{array}$ & Korelasyon kuvveti &, $948^{* *}$ &, $908^{* *}$ &, $750^{* *}$ &, $792^{* *}$ &, $789^{* *}$ \\
\hline & $\mathrm{p}<0,05$ &, 000 &, 000 &, 003 &, 001 &, 001 \\
\hline
\end{tabular}

\section{TARTIŞMA}

Serebral palsili çocuklarda mobilite düzeyleri ile toplumsal katılım becerilerin arasında ki ilişkinin incelendiği bu çalışmamızda anlamlı bir sonuç bulunmuştur. Değerlendirme sonuçları göstermektedir ki mobilite toplumsal katılım becerilerini artırmaktadır. Katılım becerilerini kısıtlayan faktörleri araştıran bir çalışmada mobilite seviyesi ile katılım arasında anlamlı sonuçlar elde edilmiş (Beckung \& Hagberg, 2002). Bizim çalışmamız Eva'nın çalışmasıyla uyumludur. Katılım parametreleri incelendiğinde mobilite seviyesi yüksek olan bireylerin evde katılım becerileri en yüksek oranda $(0,948)$ çıkmıştır. Buradan da anlaşılacağı üzere mobilite en çok evde katılım becerilerini etkilemektedir. Serebral palsili çocuklarda ve gençlerde ev, ders dışı ve toplum etkinliklerine katılma üzerine yapılan bir araştırmada da mobilite ve KMFS sisteminde üç ve üzeri mobil çocukların katılımlarının daha yüksek olduğu görülmüştür (Palisana ve ark, 2009). Bizim çalışmamız Orlin'nin bu çalışması ile uyumludur (Orlin ve ark 2010). Mobilite seviyesi düşük olsa bile bazı ailelerin çevre düzenlemeleri ve yardımcı cihazlar ile çocuğun ev içi katılım göstermesine yardımcı olduğu CAPS değerlendirmesin açık uçlu sorularından anlaşılmaktadır. Bu kişiler ile yapılan görüşmelerde 1 olgunun özel ergoterapisti olduğu ve ergoterapi müdahalelerinin toplumsal katılımı artırdığı düşünülmektedir. Mobilite seviyesi ile mahalle katıımı ilişkisi incelendiğinde, katılımcıların almış oldukları puanların mobiliteye korelasyon sonucunun değeri \%78 olarak çıkmıştır.

SP'li çocukların toplumsal katılımında kaba motor fonksiyonların etkisine bakılan bir çalışmada KMFS de 2-3 seviyeye göre 4-5 seviyede olanların katılımları daha yüksek bulunmuştur (Palisano ve ark, 2009). Bizim çalışmamız ile uyumludur. Mahalle katılımı evde katıım becerilerinde daha zorlayıcı olduğu düşünüldüğünde alınan puanların düşük olması olağandır. Engelli bireyler için fiziksel aktiviteler ve spor faaliyetlerine katılımı artırmak için öncelikle çevresel düzenlemeler ve engelliye farkındalığı artırmayı amaçlayan bir çalışmada fiziksel ortamın kötü şartlar içermesi engelli bireylerin katılım faaliyetlerini kısıtladığı bildirilmiştir (Roult ve ark. 2015). Mahalle katılımı çevresel faktörlere ve toplumun engellik bilinci ilişkili olduğu velilerin açık uçlu sorularından gözlenmektedir. Mahalle katılımında bazı olgular 'kültürel olarak farklılıklarının olması katılımımızı etkilemektedir' şeklinde bildirmişlerdir. Bizim çalışmamız da velilerden alınan bilgiler ile Roult'nun çalışması uyumludur (Roult ve ark, 2015).

Okul katılımı ile mobilite seviyesi arasındaki Korelasyon ise \%75 olarak belirlendi. Okul katılımı okulun ulaşılabilirliği ile ilişkili olduğu düşündüğünde ve değerlendirme kaynaştırma okulunda yapıldığından sonuçlar genelde yüksek bulunmuştur. SP'li çocukların okulda serbest zamanı katılımlarını araştıran bir çalışmada hareket yetenekleri yüksek olan çocukların okul içi etkinliklere atılım oranları daha yüksek bulunmuş 
(Majnemer ve ark. 2008). Bu çalıma ile bizim çalışmamı uygunluk göstermektedir. Ev ve toplumsal katılım becerileri ile mobilite sevileri arasındaki Korelasyon ise \%79 olarak belirlendi. Toplumsal katılım becerileri ile mobilite seviyesi arasında anlamlı bir fark bulundu. SP'li çocuklarda ve gençlerde ev, ders dışı ve toplum etkinliklerine katılma üzerine yapılan bir araştırmada da mobilite seviyesi yüksek olan bireylerin katılımı yüksektir (Orlin ve ark, 2009). Veliler ile yapılan görüşmelerde kişilerin toplumsal katılımları için yeterince fırsat verilmediği belirlendi. Bunun nedeni ise güvenlik problemleri olarak düşünülebilir. Ayrıca bu bireylerin arkadaş çevresi oluşturmakta da zorluklar yaşadıkları veliler tarafından bildirilmiştir. Arkadaş çevrelerinin az olduğu düşünüldüğünde toplumsal katılım için yeterli teşvik ortamın oluşmaması katılım oranın düşürdüğü düşünülmektedir. Toplumsal katılımda bazı velilerin ise 'toplu taşıma araçlarında engelli olduğu için araçlara alınmıyoruz' şeklinde bildirimleri de olmuştur. Bu çalışmada limitasyonlar ise yeterli kişi sayısına ulaşılamaması, sadece bir okulda yapılmasıdır.

Önerilerimiz ise mobilite seviyeleri ile toplumsal katılım becerileri ile ilişkili olmasından dolayı bu alanda hizmet veren meslek gurubu olan ergoterapi hizmetlerinin artırılmasıdır. Toplumun engellik bilincini ve farkındalığını artırmak için eğitim programları yapılması bu engel grubundaki çocuklar için önemlidir.

\section{Kaynaklar}

Beckung, E., \& Hagberg, G. (2002). Neuroimpairments, activity limitations, and participation restrictions in children with cerebral palsy. Dev Med Child Neurol, 44, 309-316.

Colver, P. A. , Rapp, M. , Dipl Stat, N. E., Ehlinger, V., Thyen, U., Dickinson, H.O., Parkers, J., Parkinson, K., Nystrand, M., Fauconnier, J., Marcelli, M., Michelsen, S. I., \& Arnaud, C. (2015). Self-reported quality of life of adolescents with cerebral palsy: a cross-sectional and longitudinal analysis. Lancet, 385(9969), 705-16.

Imms, C., Reilly, S., Carlin, J., \& Dodd, K. (2008). Diversity of participation in children with cerebral palsy. Dev Med Child Neurol, 50(5), 363-69.

Majnemer, A., Shevell, M., Law, M. , Birnbaum, R., Chilingaryan, G., Rosenbaum, P.,\& Poulin, C. (2008). Participation and enjoyment of leasure activities in school- aged children with cerebral palsy. Dev Med Child Neurol, 50(10), 751-758.

Morris, C. (2002). Orthotic management of children with cerebral palsy. J Prosthet Orthot, 14(4), 150-58.
Nelson, K. B., Swaiman, K. F., \& Russman, B. S. (1994). Swaiman's Pediatric Neurology Principles and Practice, Vol: 5. In K.F. Svvainman (Ed), (Second Edition, pp: 471482). Mosby.

Orlin, M. N., Palisano, R. J., Chiarello, L. A., Kang, L., Polansky, M., Almasri, N. \& Doced, J. M. (2010). Participation in home, extracurricular, and activities among children and young people with cerebral palsy. Dev Med Child Neurol, 52(2), 160-66.

Palisano, R .J., Tieman, B. L. , Walter, S. D. , Bartlett, D. J., Rosenbaum, P. L., Russell, D. J. , \& Hanna, S. E. (2003). Effect of environmental setting on mobility methods of children with cerebral palsy. Dev Med Child Neurol, 45, 113-120.

Palisano, R. J. , Kang, L., Chiarello, L. A., Orlin, M., Oeffinger, D., \& Maggs, J. (2009). Social and community participation of children and youth with cerebral palsy is associated with age and gross motor function classification. Physical Therapy, 89(12), 1304-14.

Peck, J. (2015). Activity and participation levels in 6-12-yearold children with cerebral palsy: a pilot study, year two. Faculty Scholarly Dissemination Grants, 486.

Roult, R., Brunet, I., Belley-Ranger, E., Carbonneau, H., \& Fortier, J. (2015). Inclusive sporting events in schools for youth with disability in Quebec. SAGE Open, 1-14.

Shikako-Thomas, K., Majnemer, A., Law, M., Lach, L. (2008). Determinants of participation in leisure activities in children and youth with cerebral palsy: systematic review. Phys Occup Ther Pediatr, 28(2), 155-169.

Üstdağ, E. L., Bumin, G. (2014). Investigation the effects of group activities on scial participation and sibling relationship applied to disabiled children and their sibling: a pilot study. Ergoterapi ve Rehabilitasyon Dergisi, 2(3), 141-147 